\title{
Sequential Cases of Staphylococcal Scalded Skin Syn- drome in Very Low Birth Weight Infants
}

\author{
Yoon-Joo Kim, Jae Hong Choi, and Young Mi Yoon \\ Department of Pediatrics, Jeju National University School of Medicine, Jeju, Korea
}

\section{ABSTRACT}

Staphylococcal scalded skin syndrome (4S) is an exfoliative skin disease caused by Staphylococcus aureus toxins. $4 \mathrm{~S}$ usually has a benign course in young infants and children; however, it could be fatal in preterm infants, especially very low birth weight infants. We experienced two sequential $4 \mathrm{~S}$ cases that occurred in the neonatal intensive care unit. One of the patients had complications such as bacteremia and acute kidney injury.

Key Words: Staphylococcal scaled skin syndrome; Infant, premature; Intensive care units, neonatal

\section{서론}

포도알균 열상 피부증후군(staphylococcal scalded skin syndrome, 4S)은 미숙아에서 흔하지 는 않지만, 소아에서 종종 볼 수 있는 피부 표피 탈락 질환이다. 이는 포도알균의 침습성 감염이 아닌 박리성 독소(exfoliative toxin)에 의해 발생하는 독소 매개 질환으로, 원인으로 밝혀진 독소 는 exfoliative toxin A와 B가 있고 표피 내의 가시층(stratum spinosum)과 과립층(stratum granulosum)을 분리시켜 수포를 형성하고 표피를 분리시키는 임상증상을 일으킨다 ${ }^{1)}$.

$4 \mathrm{~S}$ 는 주로 5 세 이하의 소아에서 발생하며 특별한 합병증 없이 자연적으로 좋아지는 경우가 대 부분이다. 성인에서는 소아보다 유병률이 낮지만 신손상과 관련된 사망률이 높게 나타나며 중 증도가 더 높은 것으로 보고되고 있다 ${ }^{2)}$. 또한 비교적 양성적인 경과를 보이는 소아 연령의 환자 와 비교하여, 신생아에서는 피부 탈락 범위나 정도가 더 심하며 과도한 수분 손실, 전해질 불균 형이 일어나기도 하며, 사망에 이르는 보고도 있다,34)

저자들은 신생아집중치료실에서 균혈증을 동반한 초극소 저체중출생아 1례를 포함하여 2례 의 $4 \mathrm{~S}$ 를 경험하였기에, 이를 보고하는 바이다.

본 연구는 제주대학교병원 기관생명윤리위원회의 심의 면제 승인(No. 2019-05-007)을 받았다.

\section{증례}

\section{1. 증례 1}

환자는 조절되지 않는 조기 진통으로 임신나이 28 주 4 일에 체중 $1,190 \mathrm{~g}$ 으로 질식분만을 통해
Received: 15 October 2018

Revised: 14 June 2019

Accepted: 17 June 2019

Correspondence to: Jae Hong Choi

Department of Pediatrics, Jeju National University School of Medicine, 15 Aran 13-gil, Jeju 63241, Korea Tel: +82-64-717-1476 Fax: +82-64-717-1097 E-mail: jhchoi@jejunu.ac.kr https://orcid.org/0000-0003-3284-9407
Copyright(c)

By Korean Society of Neonatology. All right reserved.

This is an Open-Access article distributed under the terms of the Creative Commons Attribution Non-Commercial License (http://creativecommons.org/licenses/ by-nc/4.0), which permits unrestricted non-commercial use, distribution, and reproduction in any medium, provided the original work is properly cited. 
출생하였다. 출생 이후 비강 양압 환기를 유지하며 지내던 중 출생 12 일째(postmenstrual day, PMA; 30주 1일) 무호흡 및 서맥이 증가 하였다. 혈액검사에서 백혈구가 $18,700 / \mathrm{mm}^{3}$ (segmental neutrophil $67.6 \%$, lymphocyte $25.4 \%$, monocyte $3.0 \%$ )으로 증가되어 있었으 나 C-반응단백은 $0.23 \mathrm{mg} / \mathrm{dL}$ 로 정상 범위 $(0.00-0.30 \mathrm{mg} / \mathrm{dL})$ 에 있었 다. 중심정맥관은 전일 제거하였으며, 모유로 수유가 잘 진행되고 있 었다. 신체 검진상, 입 위관 고정 부위 및 심전도 유도를 부착해둔 부위 에 경미한 피부 탈락이 관찰되어 뮤피로신을 도포한 뒤 지켜보았으나, 피부 탈락이 발견된 지 6시간 후에 비강 양압 환기 고정 부위(Figure 1), 채혈 후 거즈로 지혈한 부위 및 맥박 산소측정기의 센서를 감아 둔 부위에 Nikolsky sign을 동반한 피부 탈락이 관찰되었다. 호흡 자 극을 위한 카페인 투여 이외에는 복용 중인 약물은 없어, 피부 병변 및 혈액에서 배양 검사를 시행한 뒤 상기 임상증상을 바탕으로 $4 \mathrm{~S}$ 의 심 하에 vancomycin, clindamycin을 투약하였다. 항생제 투약을 시 작한 지 12 시간 후부터 피부 탈락은 더 이상 이루어지지 않았고, 출 생 15일째(PMA 30주 4일) 대부분의 피부 병변이 호전되었다. 출생 17 일째 표피 탈락이 가장 심했던 비강 양압 환기 고정 부위의 피부도 모 두 호전되었다. 피부 배양 검사에서 메티실린 감수성 황색포도알균 (methicillin-sensitive Staphylococcus aureus, MSSA)이 동정되어 항 생제 감수성 결과에 따라 vancomycin은 중단하고 clindamycin만 8 일간 유지하였다. 출생 19일째(PMA 31주 1일) 복부 엑스선 사진에 서 장관 내 가스 소견 확인되어 괴사성 장염 진단 하에 10 일간 항생 제 투여 및 금식한 뒤 합병증 없이 회복되었으며 출생 127일째(PMA 46주 4일) 퇴원한 뒤 출생 172 일째에 미숙아 망막증에 대해 레이저 수술을 받았다.

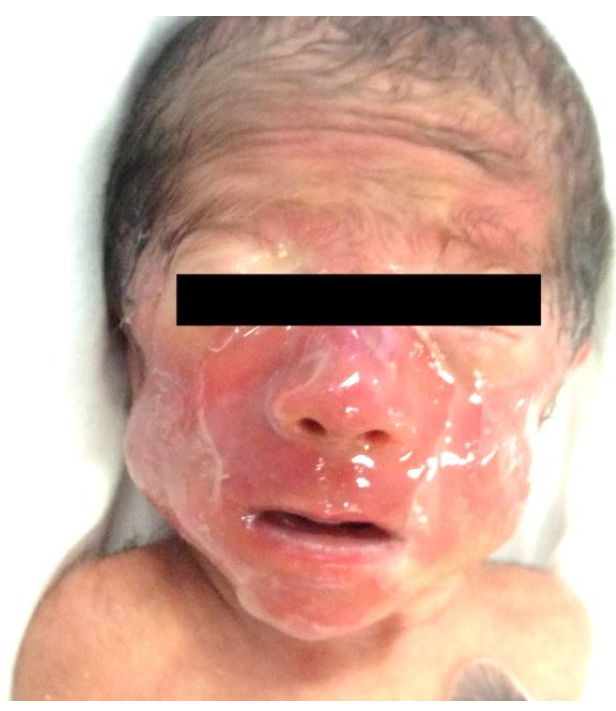

Figure 1. Placement of a continuous positive-airway pressure mask over a lesion with extensive skin peeling (use of the photo was permitted by the parents).

\section{2. 증례 2}

환자는 산모의 조절되지 않는 임신 중독증으로 응급 제왕절개술 을 통해 임신나이 26주 2일에 $610 \mathrm{~g}$ 으로 출생하였다. 인공호흡기를 통해 기계 환기 중이었고 모유와 분유로 수유하면서 중심정맥관을 통해 총 정맥 영양을 병행하던 중, 증례 1 환자에게서 피부 증상이 발 생한 지 9일 뒤인 출생 12일째(PMA 27주 6일, 체중 $610 \mathrm{~g}$ )에 동맥혈 카테터 고정 부위를 제거하면서 피부가 광범위하게 탈락되는 증상 이 확인되었다(Figure 2A). 카페인 투약 이외의 약물 투여는 없었으 며, Nikolsky sign 양성 소견으로, $4 \mathrm{~S}$ 의심 하에 cefazolin을 투약하였 다. 치료를 시작한 지 12 시간 이후까지 증상이 지속되어 기관 내 삽 관을 위해 고정한 부위 및 발뒤꿈치의 채혈 부위(Figure 2B) 등이 가 벼운 물리적 자극에도 심한 피부 탈락 소견을 보였다. 활력징후는 안정적이었으나 환자가 심하게 보채었고, 혈액검사에서 blood urea nitrogen (BUN) $36.8 \mathrm{mg} / \mathrm{dL}$, creatinine (Cr) $1.5 \mathrm{mg} / \mathrm{dL}, \mathrm{C}$-반응단백 $1.73 \mathrm{mg} / \mathrm{dL}$, 동맥혈 가스 검사상 $\mathrm{pH} 7.190$, 이산화탄소 분압 35.4 $\mathrm{mm} \mathrm{Hg}, \mathrm{HCO}_{3} 13.5 \mathrm{mmol} / \mathrm{L}$ 로 대사성 산증이 심화되어 통증 조절을 위하여 펜타닐을 투약하였으며, 불감성 수분 손실을 줄이기 위하여 인큐베이터의 습도를 90\%까지 올리도록 하였다. 피부의 탈락이 시 작된 지 36시간 경과 후 시행한 동맥혈 가스 검사상 $\mathrm{pH} 7.269$, 이산 화탄소 분압 $52.2 \mathrm{mmHg}, \mathrm{HCO}_{3} 23.9 \mathrm{mmol} / \mathrm{L}$ 로 대사성 산증이 호전

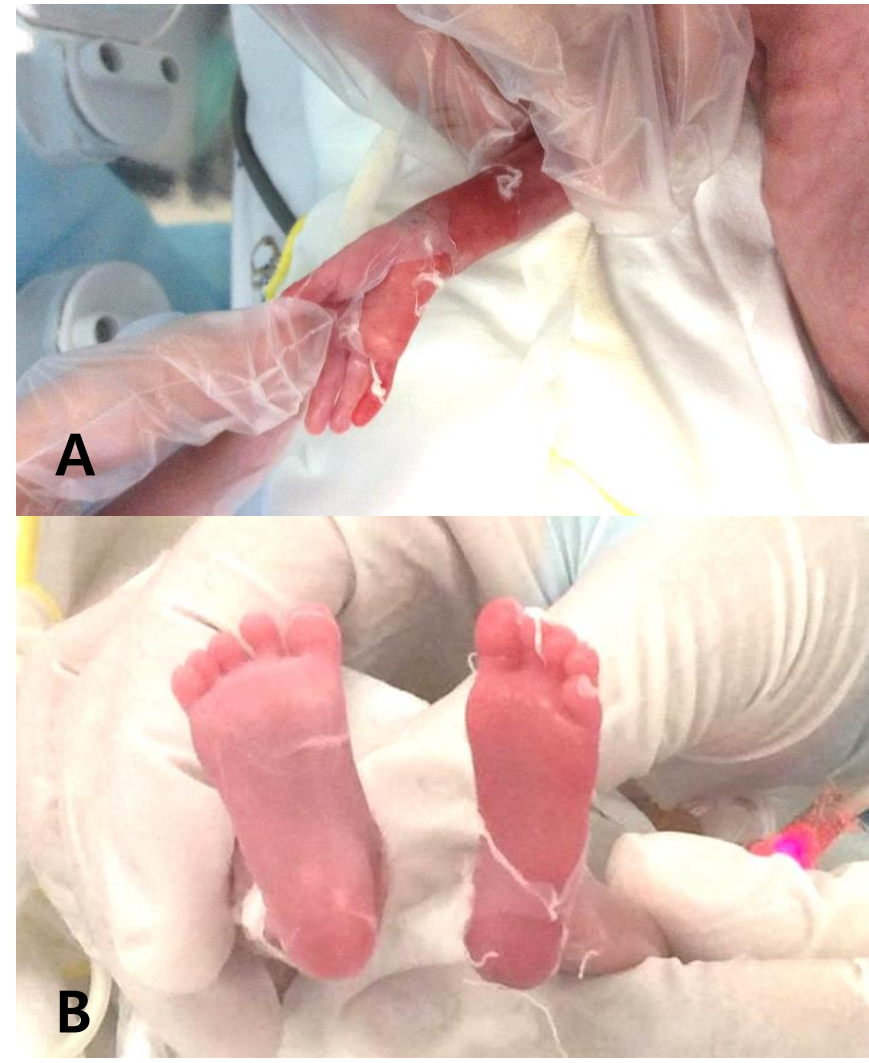

Figure 2. Placement of an arterial line catheter in a positive Nikolsky sign (A) and heel puncture site (B). 
되는 것을 확인하였다. 48 시간이 경과 후 표피 탈락이 가장 심했던 얼굴 주위의 피부는 재생이 되기 시작하였고 손목 및 발꿈치의 피부 탈락은 증상이 시작된 지 4 일 정도 경과한 뒤부터 호전되기 시작하 였다. 혈액 배양 검사 및 피부 배양 검사에서 모두 증례 1,2 와 같은 항생제 감수성을 보이는 MSSA가 동정 되었고 첫 배양 검사를 시행 한 지 이틀 뒤에 다시 검사한 혈액 배양 검사는 음성으로 확인되었으 며 혈압 저하, 의식 저하 등의 패혈증의 증후는 보이지 않았다. 환자 는 피부 증상이 시작된 이후 동맥관개존증으로 인한 심장 비대, 폐부 종 소견이 악화되어 수액 제한을 하며 경과 관찰하였으며 출생 18 일 째(PMA 28주 5일, $590 \mathrm{~g}$ )부터 소변량이 감소하며 BUN $54.2 \mathrm{mg} / \mathrm{dL}$, Cr $2.43 \mathrm{mg} / \mathrm{dL}$ 로 증가하여 출생 20 일째에 복막 카테터 삽입술을 받 았고, 출생 21일째 복막투석을 시작하여 7일간 유지한 뒤 중단하였 다. 이후 BUN 및 $\mathrm{Cr}$ 은 서서히 떨어져 PMA 31주경 정상화되었고 출 생 92일째(PMA 39주 2일) 시행한 안저 검사에서 양안의 2-3기 미숙 아 망막증이 발견되어 이의 치료를 위하여 타원으로 전원 되었다.

같은 기간 내에 신생아중환자실에 재원하고 있던 환자 중 임신나 이 36주 5일, 체중 3,140 g으로 출생한 신생아에게서 출생 7일째부 터 양측 겨드랑이 및 턱 아래에 수포성 병변이 발생하였다. Nikolsky sign은 보이지 않아 임상적으로 수포성 농가진(bullous impetigo)에 합당하였으며 이 환자의 피부 배양 검사에서 증례 환자에서 동정된 것과 같은 항생제 감수성을 보이는 황색포도알균이 확인되었다. 증 례 2 환자의 피부 병변 발생 당시 이 환자는 퇴원한 상태였으며, 두 번째 증례가 발생한 뒤 신생아중환자실에 재원 중인 모든 환자에게 비강 및 겨드랑이에서 피부 상재균 검사를 시행하였고, 손 씻기 교육 을 강화하고 장갑 착용을 의무화하였다. 피부 상재균 검사상 포도알 균이 나온 대상 환자군에는 코호트 격리 및 접촉 격리를 시행하였으 며 증례 2 환자 이후로는 추가적인 $4 \mathrm{~S}$ 환자의 발생은 없었다.

증례 1,2 환자의 피부에서 동정되었던 포도알균의 계통적 확인을 위해 multilocus sequencing test (MLST)를 시행하였고, exfoliative toxin A, B의 발현에 관련된 유전자(eta, etb)의 유무를 확인하였다. 두 개의 포도알균 모두 sequence type (ST) 121로 확인되었으며 독 소 유전자는 eta 유전자만 양성으로 확인되었다.

\section{고찰}

$4 \mathrm{~S}$ 는 신생아물집증(pemphigus neonatorum)이라고도 불리는 질환으로, 포도알균에서 분비되는 박리성 독소(exfoliative toxin) 에 의한 작용으로 표피가 분리되는 질환으로 알려져 있다. 박리성 독소는 표피 내 가시층과 과립층을 연결해주는 cadherin 물질인 desmoglein 1 에 주로 작용하며 피부층 내의 결합을 저해하여 결과 적으로 피부 탈락을 일으킨닫). 이 때문에 국소적인 수포성 농가진 의 형태로 증상이 나타날 수도 있으며, 전신에 수포를 동반한 피부
탈락의 형태로 증상이 나타날 수 있는데, 이러한 독소에 의한 피부 탈락은 대부분 포도알균의 침습성 감염 없이 발생하는 것으로 알려져 있다 ${ }^{1)}$. 일반적으로 신생아에서의 $4 \mathrm{~S}$ 는 전신형으로 나타나며 수포 형 성과 피부 탈락의 정도가 심해 입원 치료가 필요하다. 호발 연령은 6 개월에서 5세, 주로는 출생 후 2-3세경으로 신생아에 비해 피부 탈락 의 정도가 심하지 않은 경우가 많고, 표피 전체의 괴사 및 염증 세포 침윤을 보이는 독성표피괴사용해(toxic epidermal necrolysis, TEN) 와는 다르게 적절한 항생제 치료만으로 수일 내에 특별한 후유증을 남기지 않고 호전되는 경과를 보이는 것이 특징적이다. 이러한 양성 적인 경과에도 불구하고, 사망률이 3\%-11\%에 이른다는 보고가 있 으며), 사망원인은 동반된 폐렴, 전해질 이상, 패혈증으로 알려져 있 다.

$4 \mathrm{~S}$ 는 일반적으로 임상적 진단이 가능하며 수포 내부에는 균이 없 으며 콧구멍, 인두, 결막과 같은 점막층에서 포도알균을 확인하여 진단할 수 있닥. 이렇게 확인된 포도알균이 정상 피부 집락균인지 피부 탈락을 일으키는 원인균인지 확실한 감별은 어려워, 필요한 경 우 박리성 독소를 확인하거나 항독소 항체를 확인할 수도 있다. 임 상증상은 작은 자극에 의해서도 점막을 보존하는 표피의 분리가 생 기는 Nikolsky sign이 가장 특징적이며, 피부 병변에 비해 상대적으 로 전신 증상이 위중하지 않다. 그러나 피부 병변이 광범위하여 스 티븐스-존슨증후군(Stevens-Johnson syndrome), TEN과의 감별이 어려운 경우 피부 조직 검사를 시행하여 조직학적 소견을 확인해볼 수 있겠다. $4 \mathrm{~S}$ 의 조직학적 소견은 표피 내의 가시층과 과립층의 분 리이며, 표피의 괴사를 동반하지 않는다. 같은 독소로 인하여 국소 적으로 발병하는 수포성 농가진과 달리 $4 \mathrm{~S}$ 는 독소가 혈행성으로 펴 져서 발생하며, 이에 대항하는 항체가 존재하지 않을 경우 광범위한 표피 손상이 가능할 수 있다 ${ }^{8}$. 혈액 내 항독소를 이용한 여러 연구에 의하면 항독소가 제대혈에서는 $88 \%$ 검출되나, 점차 감소하여 3 개 월에서 2 세에는 $30 \%$ 까지 감소하다가 성인이 되면 $91 \%$ 까지 증가한 다는 결과가 있으며"), 미숙아를 포함한 신생아 $4 \mathrm{~S}$ 환자에서의 antiETA 항체를 검출한 한 연구에서 항독소의 농도에 따라 증상이 달라 질 수 있음을 보고한 사례를 ${ }^{10}$ 보았을 때 모체로부터 받은 항체의 양 이 적어, 항독소의 농도가 낮고, 독소의 배출이 이루어지는 신장의 기능이 미성숙한 미숙아에서 $4 \mathrm{~S}$ 의 증상이 양성적으로만 진행하지 않을 수도 있음을 유추할 수 있다.

미숙아에게서의 발생은 최근 수년간 보고가 증가하고 있으나 대 부분의 증례가 출생 후 임상적으로 안정화 된 상태에서 발생한 사례 들이며 본 증례와 같이 $610 \mathrm{~g}$ 의 작은 체중에서의 발생에 대한 보고 는 드물다. 일반적으로 $4 \mathrm{~S}$ 는 표피의 상위부위에 생기는 병변으로 대 부분 전신 증상은 경미하거나 동반하지 않으며 항생제 치료 시작 후 빠른 회복을 보여 표피의 분리도 수일 내에 회복이 되는 것으로 알려 져 있다. 그러나 일부 미숙아에게서의 발생은 저혈압, 발열, 빈맥, 무 호흡, 호흡기 증상의 악화, 전해질 이상 등의 동반 증상을 보일 수도 
있다 ${ }^{7,11-13)}$. 또한 일반적으로 균혈증을 동반하지 않는 것으로 알려져 있으나 본 증례와 같이 미숙아에서 발현할 시 포도알균 균혈증뿐만 아니라 다른 균에 의한 균혈증이 함께 발병한 것에 대한 보고도 있 었다 ${ }^{4,7)}$. 본 증례에서도 증례 1 의 경우 표피 박리가 시작됨과 동시에 무호흡의 증가는 있었으나, 항생제 치료가 시작된 지 12 시간이 경과 하자 더 이상의 표피 박리는 진행되지 않았으며, 5 일이 경과하자 모 든 병변이 호전되었다. 그러나 발병 당시 PMA 27주 6일, $610 \mathrm{~g}$ 이었 던 증례 3 의 경우 대사성 산증의 악화 외에는 전신 증상을 동반하지 않았으나, 회복되기 시작하는 시점이 2일(두부)-4일(체간)가량으로 길었고, 균혈증을 동반한 것을 미루어 보았을 때, 재태 주령이나 체 중이 질환의 경과에 영향을 미칠 수 있을 것으로 생각된다. 또한 사 망 증례들을 보았을 때 ${ }^{3,4)}$ 박리된 피부를 통한 2차 감염이 있을 경우 증상의 중증도가 더 악화할 가능성이 있다.

미숙아에서 $4 \mathrm{~S}$ 의 발병의 특이점은 질환의 중증도의 증가 이외에 도 신생아 중환자실 재원 중에 생김에 따라 이의 수평 전파에 대한 위험성, 그리고 긴 입원 경과 중에 재발의 우려가 존재한다는 데에 있다. 미숙아에서 $4 \mathrm{~S}$ 의 재발에 대해서는 소수의 증례 보고들이 있는 데 ${ }^{7,12,14)}$, 모든 환자들이 출생 체중 $1,500 \mathrm{~g}$ 미만이었으며 재발 경과 중에 일부는 균혈증을 ${ }^{7)}$ 동반하였다. 또한 수평 전파를 통한 유행에 대한 보고들이 ${ }^{12,15,16)}$ 있어 신생아실 및 신생아중환자실에서의 $4 \mathrm{~S}$ 혹 은 수포성 농가진의 발병 시 수평 전파의 위험성을 인지하고 이에 대 한 격리 조치를 취하며, 이미 회복된 환자에게서 재발의 우려 및 재 발 시 가능한 수평 전파의 가능성을 고려하여 피부 상재균에 대한 주 기적인 추적 관찰을 시행해야겠다.

$4 \mathrm{~S}$ 의 치료는 질환의 기전이 독소에 의함에도 불구하고 항생제 치 료를 권장하는 것이 일반적이다. Oxacillin에 대한 항생제 감수성 결 과에 따라 nafcillin 또는 cefazolin 혹은 vancomycin을 7-10일간 사 용하며 clindamycin이 포도알균의 독소 생성 및 합성을 저해하는 것 으로 알려져 있어 병합 요법으로 사용하기도 한다. 그러나 clindamycin에 포함된 benzyl alcohol이 미숙아에서 드물지만, toxic shock syndrome을 유발할 수 있다고 알려져 있어 신생아에서의 사용은 주 의를 요하겠다 ${ }^{8)}$. 또한 표피 탈락으로 발생하는 수분의 불감성 손실 을 보충하기 위한 수액 요법과 통증을 조절하기 위한 약제의 투약, 혈청 면역글로불린의 농도에 따라 면역글로불린의 정맥 투약을 ${ }^{10,11}$ 권장하는 연구도 있었으나, 신생아를 대상으로 한 연구에서는 면역 글로불린의 투약이 오히려 재원 기간을 증가시킨다는 보고도 있었 다 ${ }^{17)}$. 저자들의 경험에 의하면, 일단 표피의 분리가 시작되면 회복이 되기 시작 전 일정 시간 동안 작은 자극에도 광범위한 표피의 탈락이 생길 가능성이 있음으로 미숙아의 특성상 기관 삽관 및 양압 환기 마 스크 고정 부위, 정맥용 카테터를 고정하는 부위 등 불가피하게 접 착테이프를 사용해야 하는 경우가 많아, 가능한 피부에 부착이 되어 있는 부착물을 줄이는 것이 증상을 악화시키지 않는 데 도움이 되었 다.
증례 2 환아에서 발생한 급성 신부전은 이전 증례 보고에서 확인 할 수 없었던 증상이었으며 다만 성인에서 사구체신염의 발병 ${ }^{18)}$ 에 대한 보고는 있었다. 하지만 본 증례의 신부전 증상은 $4 \mathrm{~S}$ 의 결과이 기보다는 $4 \mathrm{~S}$ 의 증상 시작과 함께 악화된 동맥관개존증의 치료로 수 액 제한을 시행하였으며, $4 \mathrm{~S}$ 로 인하여 불감성 수분 손실이 늘어났으 나, 충분한 수액 공급이 되지 않아 생긴 신부전의 가능성이 더 높다 고 생각된다. 따라서 미숙아에서 수분 공급의 제한이 필요한 상황에 서 $4 \mathrm{~S}$ 의 발병이 동반되었을 경우 급성 신부전증의 가능성을 고려하 여 수액 요법에 주의를 기울여야겠다.

피부 병변의 발생 당시에 동정된 코에서 확인된 포도알균이 피부 병변을 일으킨 것과의 인과 관계가 확실하지 않은 것도 사실이다. 하지만 본 증례에서는 균혈증을 발생시킨 균과 동일한 계통(ST 121) 으로 확인되어, 질환과 비강 내 상재균과의 인과성이 확인된다. $4 \mathrm{~S}$ 를 일으키는 포도알균에 대한 국내 연구는 많지 않은데, 경남지역에 서의 한 연구에 따르면 $4 \mathrm{~S}$ 를 일으키는 포도알균 대부분은 메티실린 내성이었으며 ST 89가 절대적으로 많았다 ${ }^{19)}$. 국내뿐만 아니라 외국 에서도 $4 \mathrm{~S}$ 는 대부분 메티실린 내성 포도알균에 의해 발생한 증례들 이 대부분이었으나, 프랑스의 한 장기간 연구에서는 MSSA에 의한 증례가 많았으며 유전형도 본 증례와 같이 ST 121이 대다수였다 ${ }^{20)}$.

저자들은 신생아중환자실에서 극소 저체중출생아에서 균혈증 및 급성 신부전증을 동반한 $4 \mathrm{~S}$ 를 경험하여 이를 보고하는 바이다. 미숙 아에서의 $4 \mathrm{~S}$ 는 주로 원내 감염에 의하여 발생하며 신생아중환자실 내 유행을 유발할 수 있다. 대상 환자군의 취약한 피부, 면역체계, 신 기능에 의해 중증의 질환으로 발현할 가능성이 있으므로 주의 깊은 치료가 필요하겠다.

\section{이해관계}

본 저자는 이 논문과 관련된 이해관계가 없음.

\section{감사의 글}

본 연구는 균주의 분석을 위해 2016년도 제주대학교병원 연구비 로 수행됨.

\section{REFERENCES}

1. Wilson CB, Nizet V, Maldonado YA, Remington JS, Klein JO. Infectious diseases of the fetus and newborn infant. 8th ed. Philadelphia: Saunders/Elsevier, 2016. 
2. Patel GK, Finlay AY. Staphylococcal scalded skin syndrome: diagnosis and management. Am J Clin Dermatol 2003;4:165-75

3. Haveman LM, Fleer A, de Vries LS, Gerards LJ. Congenital staphylococcal scalded skin syndrome in a premature infant. Acta Paediatr 2004;93:1661-2.

4. Hoffmann R, Lohner M, Bohm N, Schaefer HE, Leititis J. Staphylococcal scalded skin syndrome (SSSS) and consecutive septicaemia in a preterm infant. Pathol Res Pract 1994;190:7781.

5. Amagai M, Yamaguchi T, Hanakawa Y, Nishifuji K, Sugai M, Stanley JR. Staphylococcal exfoliative toxin B specifically cleaves desmoglein 1. J Invest Dermatol 2002;118:845-50.

6. Mockenhaupt M, Idzko M, Grosber M, Schopf E, Norgauer J. Epidemiology of staphylococcal scalded skin syndrome in Germany. J Invest Dermatol 2005;124:700-3.

7. Davidson J, Polly S, Hayes PJ, Fisher KR, Talati AJ, Patel T. Recurrent staphylococcal scalded skin syndrome in an extremely lowbirth-weight neonate. AJP Rep 2017;7:e134-7.

8. Johnston GA. Treatment of bullous impetigo and the staphylococcal scalded skin syndrome in infants. Expert Rev Anti Infect Ther 2004;2:439-46.

9. Shi D, Ishii S, Sato T, Yamazaki H, Matsunaga M, Higuchi W, et al. Staphylococcal scalded skin syndrome in an extremely lowbirth-weight neonate: molecular characterization and rapid detection by multiplex and real-time PCR of methicillin-resistant Staphylococcus aureus. Pediatr Int 2011;53:211-7.

10. Saida K, Kawasaki K, Hirabayashi K, Akazawa Y, Kubota S, Kasuga E, et al. Exfoliative toxin A staphylococcal scalded skin syndrome in preterm infants. Eur J Pediatr 2015;174:551-5.

11. Kapoor V, Travadi J, Braye S. Staphylococcal scalded skin synd rome in an extremely premature neonate: a case report with a brief review of literature. J Paediatr Child Health 2008;44:374-6.

12. Rieger-Fackeldey E, Plano LR, Kramer A, Schulze A. Staphylococcal scalded skin syndrome related to an exfoliative toxin A- and B-producing strain in preterm infants. Eur J Pediatr 2002; 161:649-52.

13. Coleman JC, Dobson NR. Diagnostic dilemma: extremely low birth weight baby with staphylococcal scalded-skin syndrome or toxic epidermal necrolysis. J Perinatol 2006;26:714-6.

14. Duijsters CE, Halbertsma FJ, Kornelisse RF, Arents NL, Andriessen $\mathrm{P}$. Recurring staphylococcal scalded skin syndrome in a very low birth weight infant: a case report. J Med Case Rep 2009;3: 7313.

15. El Helali N, Carbonne A, Naas T, Kerneis S, Fresco O, Giovangrandi Y, et al. Nosocomial outbreak of staphylococcal scalded skin syndrome in neonates: epidemiological investigation and control. J Hosp Infect 2005;61:130-8.

16. Saiman L, Jakob K, Holmes KW, Whittier S, Garzon MC, Rago $\mathrm{JV}$, et al. Molecular epidemiology of staphylococcal scalded skin syndrome in premature infants. Pediatr Infect Dis J 1998;17:32934.

17. Li MY, Hua Y, Wei GH, Qiu L. Staphylococcal scalded skin syndrome in neonates: an 8-year retrospective study in a single institution. Pediatr Dermatol 2014;31:43-7.

18. Mishra AK, Yadav P, Mishra A. A systemic review on staphylococcal scalded skin syndrome (SSSS): a rare and critical disease of neonates. Open Microbiol J 2016;10:150-9.

19. Jeon H, Ma SH, Jo HJ, Woo MS, An H, Park H, et al. Long-term persistence of sequence type 89 methicillin-resistant Staphylococcus aureus isolated from cases of staphylococcal scalded skin syndrome in a Korean community. J Med Microbiol 2016; 65:1542-4.

20. Lamand V, Dauwalder O, Tristan A, Casalegno JS, Meugnier $\mathrm{H}_{\text {, }}$ Bes M, et al. Epidemiological data of staphylococcal scalded skin syndrome in France from 1997 to 2007 and microbiological characteristics of Staphylococcus aureus associated strains. Clin Microbiol Infect 2012;18:E514-21. 